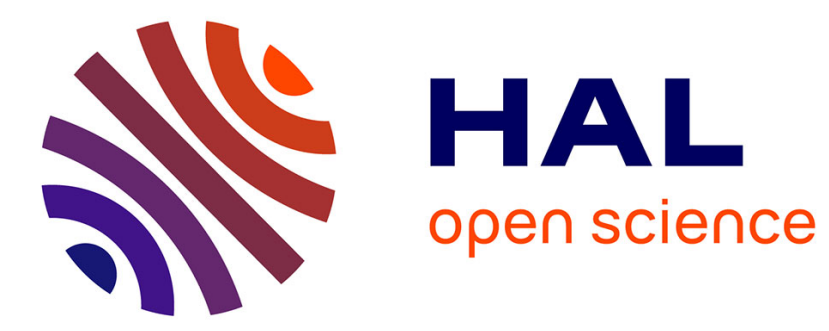

\title{
On the Dynamics of unemployment and wage Distributions
}

\author{
Jean-Marc Robin
}

\section{To cite this version:}

Jean-Marc Robin. On the Dynamics of unemployment and wage Distributions. Econometrica, 2011, 79 (5), pp.1327-1355. hal-01024463

\section{HAL Id: hal-01024463 \\ https://hal-sciencespo.archives-ouvertes.fr/hal-01024463}

Submitted on 16 Jul 2014

HAL is a multi-disciplinary open access archive for the deposit and dissemination of scientific research documents, whether they are published or not. The documents may come from teaching and research institutions in France or abroad, or from public or private research centers.
L'archive ouverte pluridisciplinaire HAL, est destinée au dépôt et à la diffusion de documents scientifiques de niveau recherche, publiés ou non, émanant des établissements d'enseignement et de recherche français ou étrangers, des laboratoires publics ou privés. 


\section{ECONOMETRICA}

JOURNAL OF THE ECONOMETRIC SOCIETY

An International Society for the Advancement of Economic Theory in its Relation to Statistics and Mathematics

http://www.econometricsociety.org/

Econometrica, Vol. 79, No. 5 (September, 2011), 1327-1355

ON THE DYNAMICS OF UNEMPLOYMENT

AND WAGE DISTRIBUTIONS

JEAN-MARC ROBIN

Sciences Po, 75007 Paris, France and University College London

The copyright to this Article is held by the Econometric Society. It may be downloaded, printed and reproduced only for educational or research purposes, including use in course packs. No downloading or copying may be done for any commercial purpose without the explicit permission of the Econometric Society. For such commercial purposes contact the Office of the Econometric Society (contact information may be found at the website http://www.econometricsociety.org or in the back cover of Econometrica). This statement must be included on all copies of this Article that are made available electronically or in any other format. 


\title{
ON THE DYNAMICS OF UNEMPLOYMENT AND WAGE DISTRIBUTIONS
}

\author{
BY JEAN-MARC ROBIN ${ }^{1}$
}

\begin{abstract}
Postel-Vinay and Robin's (2002) sequential auction model is extended to allow for aggregate productivity shocks. Workers exhibit permanent differences in ability while firms are identical. Negative aggregate productivity shocks induce job destruction by driving the surplus of matches with low ability workers to negative values. Endogenous job destruction coupled with worker heterogeneity thus provides a mechanism for amplifying productivity shocks that offers an original solution to the unemployment volatility puzzle (Shimer (2005)). Moreover, positive or negative shocks may lead employers and employees to renegotiate low wages up and high wages down when agents' individual surpluses become negative. The model delivers rich business cycle dynamics of wage distributions and explains why both low wages and high wages are more procyclical than wages in the middle of the distribution.
\end{abstract} ing.

KEYWORDS: Unemployment dynamics, wage distribution, inequality, search-match-

\section{INTRODUCTION}

THE MAIN MOTIVATION for this paper is to explore the role of heterogeneous worker ability in a search-matching model of unemployment and wages with aggregate productivity shocks. There has recently been considerable interest for noncompetitive macrodynamic models of the labor market with heterogeneous agents. The monumental empirical literature on wage equations has long demonstrated the importance of worker and firm heterogeneity in wage dispersion; and the possibility of separately identifying a distribution of worker characteristics and a distribution of firm characteristics is in itself an indication that the process of matching workers to jobs is not competitive (see Mortensen (2005)). In the macroeconomic literature, the role of search frictions as a cause for unemployment is now well understood (e.g., Mortensen and Pissarides (1994)). It was only a matter of time before the macroeconomic and the microeconomic search-matching literatures converged.

This question admittedly calls for different answers, depending on the way search frictions are modelled. For example, Moscarini and Postel-Vinay $(2008,2009)$ studyied the non-equilibrium dynamics of the Burdett-Mortensen

\footnotetext{
${ }^{1}$ This article is based on my Walras-Bowley Lecture, presented at the North American Summer Meetings of the Econometric Society, Boston University, June 2009. Helpful comments were received from participants in seminars at IFS, Stockholm University, Sciences Po, CRESTINSEE, Cambridge University, the Paris School of Economics, and conferences at the Milton Friedman Institute (University of Chicago), Jerusalem (Bank of Israel), and Venice (CSEifo). I am particularly grateful to Rob Shimer, Iouri Manovskii, Jean-Olivier Hairault, Thomas Piketty, Pierre Cahuc, Francis Kramarz, Guy Laroque, Boyan Jovanovic, Tom Sargent, and Fabien PostelVinay whose questions and comments have definitely influenced this paper.
} 
wage posting model. Workers are identical but firms are different. This model yields very interesting insights on the business-cycle dynamics of firm size distributions. Menzio and Shi $(2009,2010 \mathrm{a})$ also considered a wage posting model, but they assumed directed search in lieu of random search. The model is elegant and easy to solve in and out of the steady state because the equilibrium is block-recursive and agents only need to forecast the exogenous aggregate shocks. However, with directed search, the distance that these frictions introduce with a purely competitive equilibrium is rather minimal. For example, with ex ante heterogeneous workers, the labor market is perfectly segmented: any active submarket is visited by only one type of worker (Menzio and Shi (2010b)) so that search frictions do not seem to generate mismatch in this setup.

In this paper, as in Moscarini and Postel-Vinay, I also assume random search, but assume wage bargaining instead of wage posting. The recent survey by Hall and Krueger (2010) showed mixed evidence about whether workers bargain over pay before accepting a job (about one hire in three) or whether they had precise information about pay before their first meeting with an employer (another third). Now bargaining offers a considerable gain in simplicity with respect to wage posting as far as modelling is concerned. This is because, with wage posting, complicated strategic interactions have to be accounted for. Hall and Krueger also noted that about $40 \%$ of workers could have remained on their earlier jobs at the time that they accept their new job. This indicates that it is important for any model of employment and turnover to allow for on-thejob search.

To introduce on-the-job search in a bargaining model, I use Postel-Vinay and Robin's (2002) sequential auction model in a similar way to Lise, Meghir, and Robin (2009) except than I allow for aggregate shocks to productivity instead of firm-specific shocks. Wage contracts are long term contracts that can be renegotiated by mutual agreement only. Employees search on the job and employers counter outside offers. It is assumed that firms have full monopsony power vis-à-vis unemployed workers and hire them at a wage that is only marginally greater than their reservation wage. A worker paid such a low wage has a strong incentive to look for an alternative employer and trigger Bertrand competition. Bertrand competition between identical firms raises the wage to the maximal wage firms are willing to pay, that is, the wage that gives the employer a negligible share of the surplus.

In this environment, any steady-state equilibrium is such that each worker type is associated with only two wages: a starting wage and a promotion wage, which are the lower and the upper bounds of the bargaining set-either the firm or the worker gets all the surplus. Aggregate productivity shocks multiply the number of potential couples of wages, many of which have a positive probability of being observed in any state of nature because of the stickiness induced by long term contracting.

The model offers a theoretical framework to study the link between the dynamics of average wages (the usual concern of representative-agent models) 
and the dynamics of individual wages. In particular, it explains why different wage deciles can exhibit different volatilities and different responses to productivity shocks.

A second important application of the model concerns the link between unemployment and business cycle. In a very influential paper, Shimer (2005) argued that the search-matching model of Mortensen and Pissarides (1994) cannot reproduce unemployment dynamics well. The reason is that with wage renegotiation in every period, any productivity shock is immediately absorbed into the wage with little effect on unemployment. A long series of papers have tried to solve the puzzle, essentially by making wages sticky (Hall (2005), Hall and Milgrom (2008), Gertler and Trigari (2009), Pissarides (2009)) or by reducing the match surplus to a very small value (Hagedorn and Manovskii (2008)). ${ }^{2}$

Interestingly, although endogenous job destruction is at the heart of the Mortensen-Pissarides model, this literature has neglected endogenous job destruction as a possible amplifying mechanism when coupled with worker or match heterogeneity. Yet, it is easy to understand that if frictional unemployment due to exogenous job destruction shocks is about $4 \%$ and if a fraction of $6 \%$ of low-skilled workers are at risk of negative surplus when aggregate productivity goes below a certain threshold, then one has a simple way to explain how unemployment can vary between $4 \%$ and $10 \%$ with a volatility that is 10 times greater than the volatility of productivity. ${ }^{3}$

The paper is organized as follows. A dynamic sequential-auction model with heterogeneous workers and identical firms is first developed. The DSGE model is recursive with only one aggregate state variable, labor productivity, so that it can be easily simulated in and out of the steady-state equilibrium. Then the model's parameters are estimated by simulated generalized method of moments (GMM), and the results are interpreted.

\section{THE MODEL}

\subsection{Setup}

\subsubsection{Aggregate Shocks}

Time is discrete and indexed by $t \in \mathbb{N}$. The global state of the economy is an ergodic Markov chain $y_{t} \in\left\{y_{1}<\cdots<y_{N}\right\}$ with transition matrix $\boldsymbol{\Pi}=\left(\pi_{i j}\right)$

\footnotetext{
${ }^{2}$ Mortensen and Nagypál (2007) reviewed this literature and considered alternative mechanisms. Pissarides (2009) suggested a novel approach to solve the unemployment volatility puzzle by assuming that productivity shocks change entry wages in new jobs differently from wages in ongoing jobs. My model follows Pissarides's suggestion, as entry changes are also different from later wages. Gertler and Trigari (2009) generated wage stickiness using a Calvo-type mechanism such that only a fraction of contracts are renegotiated in every period. Both models generate cross-sectional wage dispersion, but they do not address the issue of wage inequality dynamics.

${ }^{3}$ The specification calibrated in this paper will have a continuum of worker types and a smoother response of unemployment to aggregate productivity shocks.
} 
(with a slight abuse of notation, $y_{t}$ denotes the stochastic process and $y_{i}$ denotes an element of the support). Aggregate shocks accrue at the beginning of each period.

\subsubsection{Workers}

There are $M$ types of workers and $\ell_{m}$ workers of each type (with $\sum_{m=1}^{M} \ell_{m}=$ 1). Each type $m=1, \ldots, M$ is characterized by a time-invariant ability $x_{m}$, with $x_{m}<x_{m+1}$. Workers are paired with identical firms to form productive units. The per-period output of a worker of ability $x_{m}$ when aggregate productivity is $y_{i}$ is denoted as $y_{i}(m)$. In the application we shall set $y_{i}(m)=x_{m} y_{i}$. This seems the most neutral specification as far as the cyclicality of relative match productivity dispersion is concerned, that is, $y_{i}(m) / y_{i}\left(m^{\prime}\right)$ only depends on worker types $m$ and $m^{\prime}$, not on the economy's state $i$. We denote by $S_{t}(m)$ the surplus of a match including a worker of type $x_{m}$, that is, the present value of the match minus the value of unemployment and minus the value of a vacancy (assumed to be nil). Only matches with positive surplus $S_{t}(m)>0$ are viable.

\subsubsection{Turnover}

Matches form and break at the beginning of each period, after the aggregate state has been reset. Let $u_{t}(m)$ denote the proportion of unemployed in the population of workers of ability $x_{m}$ at the end of period $t-1$, and let $u_{t}=\sum_{m=1}^{M} u_{t}(m) \ell_{m}$ define the aggregate unemployment rate. A the beginning of period $t$, a fraction $\mathbf{1}\left\{S_{t}(m) \leq 0\right\}\left[1-u_{t}(m)\right] \ell_{m}$ is endogenously laid off-or temporarily decides to become inactive-and another fraction $\delta \mathbf{1}\left\{S_{t}(m)>0\right\}\left[1-u_{t}(m)\right] \ell_{m}$ is exogenously destroyed.

Firms cannot direct their search to specific worker types. For simplicity and to discipline the model as much as possible, I also assume that workers meet employers at exogenous rates. It is yet straightforward to work out an extension with a general matching function. Thus, a fraction $\lambda_{0} \mathbf{1}\left\{S_{t}(m)>\right.$ $0\} u_{t}(m) \ell_{m}$ of employable unemployed workers meet an employer and a fraction $\lambda_{1}(1-\delta) \mathbf{1}\left\{S_{t}(m)>0\right\}\left[1-u_{t}(m)\right] \ell_{m}$ of employees meet an alternative employer, where $\lambda_{0}$ and $\lambda_{1}$ are the respective search intensities of unemployed and employed workers. ${ }^{4}$

\subsubsection{Wages}

Employers have full monopsony power with respect to workers. Hence, unemployed workers are offered their reservation wage, the employer taking all the surplus. Rent sharing accrues via on-the-job search, triggering competition between employers for workers. Because firms are identical and there is no

\footnotetext{
riod.

${ }^{4}$ Unproductive unemployed workers search because they may turn productive in the next pe-
} 
mobility cost, Bertrand competition transfers the whole surplus to the worker, who then gets paid the firm's reservation value. This wage dynamics is similar to the optimal wage-tenure contracts studied by Stevens (2004). She showed that an infinity of wage-tenure contracts are optimal. In particular, employers could pay the workers their productivity and charge them an entry fee.

All firms being identical, a worker is indifferent between staying with the incumbent employer or moving to the poacher. I assume that the tie is broken in favor of the poacher with probability $\tau .^{5}$

\subsubsection{Turnover Rates}

The following turnover rates can then be computed.

- Exit rate from unemployment:

$$
f_{t}=\lambda_{0} \frac{\sum_{m} \mathbf{1}\left\{S_{t}(m)>0\right\} u_{t}(m) \ell_{m}}{u_{t}} .
$$

- Quit rate (job-to-job mobility):

$$
q_{t}=\tau \lambda_{1}(1-\delta) \frac{\sum_{m} \mathbf{1}\left\{S_{t}(m)>0\right\}\left[1-u_{t}(m)\right] \ell_{m}}{1-u_{t}} .
$$

- Job destruction rate:

$$
s_{t}=\delta+(1-\delta) \frac{\sum_{m} \mathbf{1}\left\{S_{t}(m) \leq 0\right\}\left(1-u_{t}(m)\right) \ell_{m}}{1-u_{t}} .
$$

Notice that the quit rate and the job separation rate are related by the deterministic relationship $q_{t}=\tau \lambda_{1}\left(1-s_{t}\right)$.

\subsection{Unemployment Dynamics}

\subsubsection{The Value of Unemployment}

Let $U_{i}(m)$ denote the present value of remaining unemployed for the rest of period $t$ for a worker of type $m$ if the economy is in state $i$. We do not index this value by any state variable other than the state of the economy for reasons that will immediately become clear. An unemployed worker receives a flow payment $z_{i}(m)$ for the period. At the beginning of the next period, the state of

\footnotetext{
${ }^{5}$ The randomness in the eventual mobility may explain why employers engage in Bertrand competition in the first place if part of the outcome of the production process is nontransferable.
} 
the economy changes to $y_{j}$ with probability $\pi_{i j}$ and the worker receives a job offer with some probability. However, because the employer has full monopsony power and takes the whole surplus, the present value of a new job to the worker is only marginally better than the value of unemployment. Consequently, the value of unemployment solves the linear Bellman equation

$$
U_{i}(m)=z_{i}(m)+\frac{1}{1+r} \sum_{j} \pi_{i j} U_{j}(m) .
$$

\subsubsection{The Match Surplus}

After a productivity shock from $i$ to $j$, all matches yielding negative surplus are destroyed. Otherwise, if the worker is poached, Bertrand competition transfers the whole surplus to the worker whether she moves or not. The surplus of a match with a worker of type $m$ when the economy is in state $i$ thus solves the Bellman equation

$$
S_{i}(m)=y_{i}(m)-z_{i}(m)+\frac{1-\delta}{1+r} \sum_{j} \pi_{i j} \max \left\{S_{j}(m), 0\right\} .
$$

This almost linear system can be solved numerically by value-function iterations. As for the unemployment value, the match surplus only depends on the state of the economy, and in particular not on calendar time. Hence the match surplus process for workers of type $m, S_{t}(m)$, is also a Markov chain with support $\left\{S_{i}(m), i=1, \ldots, N\right\}$ and transition matrix $\boldsymbol{\Pi}$.

\subsubsection{The Unemployment Process}

The joint process of $u_{t}(m)$ and $S_{t}(m)$ or $u_{t}(m)$ and $\mathbf{1}\left\{S_{t}(m)>0\right\}$ is Markovian, the law of motion of individual-specific unemployment rates being

$$
\begin{aligned}
u_{t+1}(m) & =1-\left[(1-\delta)\left(1-u_{t}(m)\right)+\lambda_{0} u_{t}(m)\right] \mathbf{1}\left\{S_{t}(m)>0\right\} \\
& = \begin{cases}1, & \text { if } S_{t}(m) \leq 0, \\
u_{t}(m)+\delta\left(1-u_{t}(m)\right)-\lambda_{0} u_{t}(m), & \text { if } S_{t}(m)>0 .\end{cases}
\end{aligned}
$$

Unemployment dynamics is thus independent of how the surplus is split between employers and employees. Thus, aggregate shocks are transmitted to unemployment independently of how wages are determined.

\subsubsection{Steady State}

In state $i$ 's steady-state equilibrium, the unemployment rate in group $m$ is

$$
u_{i}(m)=\frac{\delta}{\delta+\lambda_{0}} \mathbf{1}\left\{S_{i}(m)>0\right\}+\mathbf{1}\left\{S_{i}(m) \leq 0\right\} .
$$


The aggregate unemployment rate follows as

$$
u_{i}=\sum_{m=1}^{M} u_{i}(m) \ell_{m}=\frac{\delta}{\delta+\lambda_{0}} L_{i}+1-L_{i}=1-\frac{\lambda_{0}}{\delta+\lambda_{0}} L_{i},
$$

where $L_{i}=\sum_{m=1}^{M} \ell_{m} \mathbf{1}\left\{S_{i}(m)>0\right\}$ is the number of employable workers.

The state-contingent equilibrium unemployment values are bounded from below by $\frac{\delta}{\delta+\lambda_{0}}$. The aggregate unemployment rate is greater than this lower bound when a low aggregate productivity value $y_{i}$ induces endogenous job destruction or nonparticipation $\left(L_{i}<1\right.$ in steady state).

\subsection{Wages}

\subsubsection{The Worker Surplus}

Let $W_{i}(w, m)$ denote the present value of a wage $w$ in state $i$ to a worker of type $m$. The surplus flow for the current period is $w-z_{i}(m)$. In the following period, the worker is laid off with probability $\mathbf{1}\left\{S_{j}(m) \leq 0\right\}+\delta \mathbf{1}\left\{S_{j}(m)>0\right\}$ and suffers zero surplus. Otherwise, with probability $\lambda_{1}$, the worker receives an outside offer and enjoys the whole surplus. In the absence of poaching (with probability $1-\lambda_{1}$ ), wage contracts may still be renegotiated if a productivity shock moves the current wage outside the bargaining set. We follow MacLeod and Malcomson (1993) and the recent application by Postel-Vinay and Turon (2010), and assume that the new wage contract is the closest point in the bargaining set to the old, now infeasible wage. That is, if $W_{j}(w, m)-U_{j}(m)<0$, the worker has a credible threat to quit to unemployment and her employer accepts renegotiation of the wage up to the point where the worker obtains zero surplus. If $W_{j}(w, m)-U_{j}(m)>S_{j}(m)$, the employer has a credible threat to fire the worker unless she accepts renegotiation downward to the point where she gets the whole surplus and no more. tion

The worker surplus, $W_{i}(w, m)-U_{i}(m)$, therefore satisfies the Bellman equa-

$$
\begin{aligned}
W_{i}(w, m)-U_{i}(m)= & w-z_{i}(m) \\
& +\frac{1-\delta}{1+r} \sum_{j} \pi_{i j} \mathbf{1}\left\{S_{j}(m)>0\right\} \\
& \times\left[\lambda_{1} S_{j}(m)+\left(1-\lambda_{1}\right)\left(W_{j}^{*}(w, m)-U_{j}(m)\right)\right],
\end{aligned}
$$

where

$$
W_{j}^{*}(w, m)-U_{j}(m)=\min \left\{\max \left\{W_{j}(w, m)-U_{j}(m), 0\right\}, S_{j}(m)\right\}
$$

is the renegotiated worker surplus. 
Note that here again there is only one aggregate state variable: aggregate productivity. The assumption that the rate of offer arrival is exogenous is important to justify this point. With a matching function, the unemployment rate should be included in the state space. However, a very good approximation would be obtained by assuming that the unemployment rate and market tightness jump to their steady-state value after a productivity shock.

\subsubsection{The Set of Equilibrium Wages}

For all aggregate states $y_{i}$ and all worker types $x_{m}$, there are only two possible wages. Either the worker was offered a job while unemployed and she can only claim a wage $\underline{w}_{i}(m)$ such that $W_{i}\left(\underline{w}_{i}(m), m\right)=U_{i}(m)$ (her reservation wage) or she was already employed and she benefits from a wage rise to $\bar{w}_{i}(m)$ such that $W_{i}\left(\bar{w}_{i}(m), m\right)=U_{i}(m)+S_{i}(m)$ (the employer's reservation value).

I now explain how these wages can be solved for. For all $k$, let us denote the worker surpluses when the economy is in state $k$ and wages are either $\underline{w}_{i}(m)$ or $\bar{w}_{i}(m)$ as

$$
\begin{aligned}
& \underline{W}_{k, i}(m)=W_{k}\left(\underline{w}_{i}(m), m\right)-U_{k}(m), \\
& \bar{W}_{k, i}(m)=W_{k}\left(\bar{w}_{i}(m), m\right)-U_{k}(m),
\end{aligned}
$$

and let also

$$
\begin{aligned}
& \underline{W}_{k, i}^{*}(m)=\min \left\{\max \left\{\underline{W}_{k, i}(m), 0\right\}, S_{i}(m)\right\}, \\
& \bar{W}_{k, i}^{*}(m)=\min \left\{\max \left\{\bar{W}_{k, i}(m), 0\right\}, S_{i}(m)\right\} .
\end{aligned}
$$

Making use of the definitions of wages, we find that $\underline{W}_{i, i}(m)=0$ and $\bar{W}_{i, i}(m)=$ $S_{i}(m)$. These worker surpluses therefore satisfy the following modified Bellman equations:

$$
\begin{aligned}
\underline{W}_{k, i}(m)= & \underline{W}_{k, i}(m)-\underline{W}_{i, i}(m) \\
= & z_{i}(m)-z_{k}(m)+\frac{1-\delta}{1+r} \sum_{j}\left(\pi_{k j}-\pi_{i j}\right) \\
& \times \mathbf{1}\left\{S_{j}(m)>0\right\}\left[\lambda_{1} S_{j}(m)+\left(1-\lambda_{1}\right) \underline{W}_{j, i}^{*}(m)\right]
\end{aligned}
$$

and

$$
\begin{aligned}
\bar{W}_{k, i}(m)-S_{i}(m)= & \bar{W}_{k, i}(m)-\bar{W}_{i, i}(m) \\
= & z_{i}(m)-z_{k}(m)+\frac{1-\delta}{1+r} \sum_{j}\left(\pi_{k j}-\pi_{i j}\right) \\
& \times \mathbf{1}\left\{S_{j}(m)>0\right\}\left[\lambda_{1} S_{j}(m)+\left(1-\lambda_{1}\right) \bar{W}_{j, i}^{*}(m)\right] .
\end{aligned}
$$


Value-function iteration delivers a simple numerical solution algorithm, using for a starting value the solution of the linear system that is obtained by removing the "stars" from the continuation values.

Having determined $\underline{W}_{k, i}(m)$ and $\bar{W}_{k, i}(m)$ for all $k, i$, and $m$, wages then follow as

$$
\begin{aligned}
\underline{w}_{i}(m)= & z_{i}(m)-\frac{1-\delta}{1+r} \sum_{j} \pi_{i j} 1\left\{S_{j}(m)>0\right\} \\
& \times\left[\lambda_{1} S_{j}(m)+\left(1-\lambda_{1}\right) \underline{W}_{j, i}^{*}(m)\right]
\end{aligned}
$$

and

$$
\begin{aligned}
\bar{w}_{i}(m)= & S_{i}(m)+z_{i}(m)-\frac{1-\delta}{1+r} \sum_{j} \pi_{i j} \mathbf{1}\left\{S_{j}(m)>0\right\} \\
& \times\left[\lambda_{1} S_{j}(m)+\left(1-\lambda_{1}\right) \bar{W}_{j, i}^{*}(m)\right] .
\end{aligned}
$$

\subsubsection{The Dynamics of Wage Distributions}

The support of the wage distribution is the union of all sets $\Omega_{m}=\left\{\underline{w}_{i}(m)\right.$, $\left.\bar{w}_{i}(m), \forall i\right\}$. Let $g_{t}(w, m)$ denote the measure of workers of ability $m$ employed at wage $w \in \Omega$ at the end of period $t-1$.

Conditional on $y_{t}=y_{i}$ (maybe equal to $y_{t-1}$ ) at the beginning of period $t$, no worker can be employed if $S_{i}(m) \leq 0$. The inflow to the stock of workers paid the minimum wage $\underline{w}_{i}(m)$ is otherwise made of all unemployed workers drawing an offer $\left(\lambda_{0} u_{t}(m) \ell_{m}\right)$ plus all employees paid a wage $w$ such that $W_{i}(w, m)-U_{i}(m)<0$, who were not laid off but still were not lucky enough to get poached. The outflow is made of those workers previously paid $\underline{w}_{i}(m)$ who are either laid off or poached. That is,

$$
\begin{aligned}
g_{t+1} & \left(\underline{w}_{i}(m), m\right) \\
= & \mathbf{1}\left\{S_{i}(m)>0\right\} \\
& \times\left[\lambda_{0} u_{t}(m) \ell_{m}+(1-\delta)\left(1-\lambda_{1}\right)\right. \\
\times & \left.\left(g_{t}\left(\underline{w}_{i}(m), m\right)+\sum_{w \in \Omega_{m}} \mathbf{1}\left\{W_{i}(w, m)-U_{i}(m)<0\right\} g_{t}(w, m)\right)\right] .
\end{aligned}
$$

The inflow to the stock of workers paid $\bar{w}_{i}(m)$ has two components. First, any employee paid less than $\bar{w}_{i}(m)$ (in present value terms) who is contacted by another employer benefits from a pay rise to $\bar{w}_{i}(m)$. Second, any employee paid more than $\bar{w}_{i}(m)$ (in present value) has to accept a pay cut to $\bar{w}_{i}(m)$ to 
avoid layoff. The only reason to flow out is layoff. Hence,

$$
\begin{aligned}
g_{t+1}\left(\bar{w}_{i}(m), m\right) & =\mathbf{1}\left\{S_{i}(m)>0\right\}(1-\delta) \\
& \times\left[\lambda_{1}\left(1-u_{t}(m)\right) \ell_{m}+\left(1-\lambda_{1}\right)\right. \\
& \times\left(g_{t}\left(\bar{w}_{i}(m), m\right)\right. \\
+ & \left.\left.\sum_{w \in \Omega_{m}} \mathbf{1}\left\{W_{i}(w, m)-U_{i}(m)>S_{i}(m)\right\} g_{t}(w, m)\right)\right] .
\end{aligned}
$$

For all $w \in \Omega_{m} \backslash\left\{\underline{w}_{i}(m), \bar{w}_{i}(m)\right\}$, only those workers paid $w$ greater than $\underline{w}_{i}(m)$ and less than $\bar{w}_{i}(m)$ (in value terms), who are not laid off or poached, keep their wage:

$$
\begin{aligned}
g_{t+1}(w, m)=\mathbf{1}\left\{S_{i}(m)>0\right\}(1-\delta)\left(1-\lambda_{1}\right) \\
\\
\times \mathbf{1}\left\{0 \leq W_{i}(w, m)-U_{i}(m) \leq S_{i}(m)\right\} g_{t}(w, m) .
\end{aligned}
$$

Note that summing $g_{t+1}(w, m)$ over all wages and dividing by $\ell_{m}$ yields the law of motion for the unemployment rates $u_{t}(m)$ :

$$
1-u_{t+1}(m)=\mathbf{1}\left\{S_{i}(m)>0\right\}\left[\lambda_{0} u_{t}(m)+(1-\delta)\left(1-u_{t}(m)\right)\right] .
$$

The joint process of distributions and surpluses is Markovian with a finite state space. In principle one can certainly calculate its ergodic distribution, but this is a rather cumbersome calculation. In practice, I shall use simulations to approximate the theoretical moments to match with the data moments used for the estimation of structural parameters (Robin (2011)).

\section{DATA}

\subsection{Monthly Unemployment}

I use the Bureau of Labor Statistics's (BLS) series of seasonally adjusted monthly employment and unemployment levels of all employees, 16 years and over, constructed from the Current Population Survey (CPS). The BLS also offers to decompose unemployment according to unemployment duration (less than 5 weeks, between 5 and 14, more than 15 , and more than 27 weeks) ${ }^{6}$

${ }^{6}$ Series LNS12000000, LNS13000000, LNS13008396, LNS008756, LNS0085145, and LNS008636. 
Following usual pratice, I then construct the series of exit rates from unemployment and job destruction rates from unemployment flows as

$$
\begin{aligned}
& f=1-(F . U-F . U 5) / U, \\
& s=F . U 5 / E,
\end{aligned}
$$

where $U$ and $U 5$ denote total unemployment and unemployment with less than 5 weeks duration, $E$ is total employment, and $F$ is the forward operator.

The Job Openings and Labor Turnover Survey (JOLTS) offers an alternative and independent way to calculate these rates. Let $H, S$, and $Q$, respectively, denote the BLS series of hires, total separations, and quits. ${ }^{7}$ Let then

$$
\begin{aligned}
& f_{\text {JOLTS }}=(H-Q) / U, \\
& s_{\text {JOLTS }}=(S-Q) / E, \\
& q_{\text {JOLTS }}=Q / E .
\end{aligned}
$$

Figure 1 shows that both couples of series $\left(f, f_{\text {JOLTS }}\right)$ and $\left(s, s_{\text {JOLTS }}\right)$ are sufficiently close to cast doubts on the necessity to adjust $f$ and $s$ for the rupture in the continuity of the CPS in the 1990s.

With exponentially distributed unemployment duration and homogeneous workers, the distribution of elapsed duration in the stock is also exponential with the same distribution as in the population. One can thus construct alternative series of exit rates as

$$
\begin{aligned}
& f 5=-4 \times \log (U 5 p / U) / 5, \\
& f 15=-4 \times \log (U 15 p / U) / 15, \\
& f 27=-4 \times \log (U 27 p / U) / 27,
\end{aligned}
$$

where $U 5 p, U 15 p$, and $U 27 p$ denote the number of unemployed workers with duration greater than 5,15 , and 27 weeks, and where the multiple 4 is used to adjust for durations being measured in weeks instead of months. Figure 2 displays these different series. The fact that $f 5>f 15>f 27$ clearly suggests heterogeneous rates among unemployed workers.

\subsection{Quarterly Series}

I use the BLS quarterly series of seasonally adjusted real output per person in the non-farm business sector to construct the aggregate productivity process. For wages, I use hourly compensation divided by the implicit output deflator,

${ }^{7}$ Series JTS00000000HIL, JTS00000000TSL, and JTS00000000QUL. 

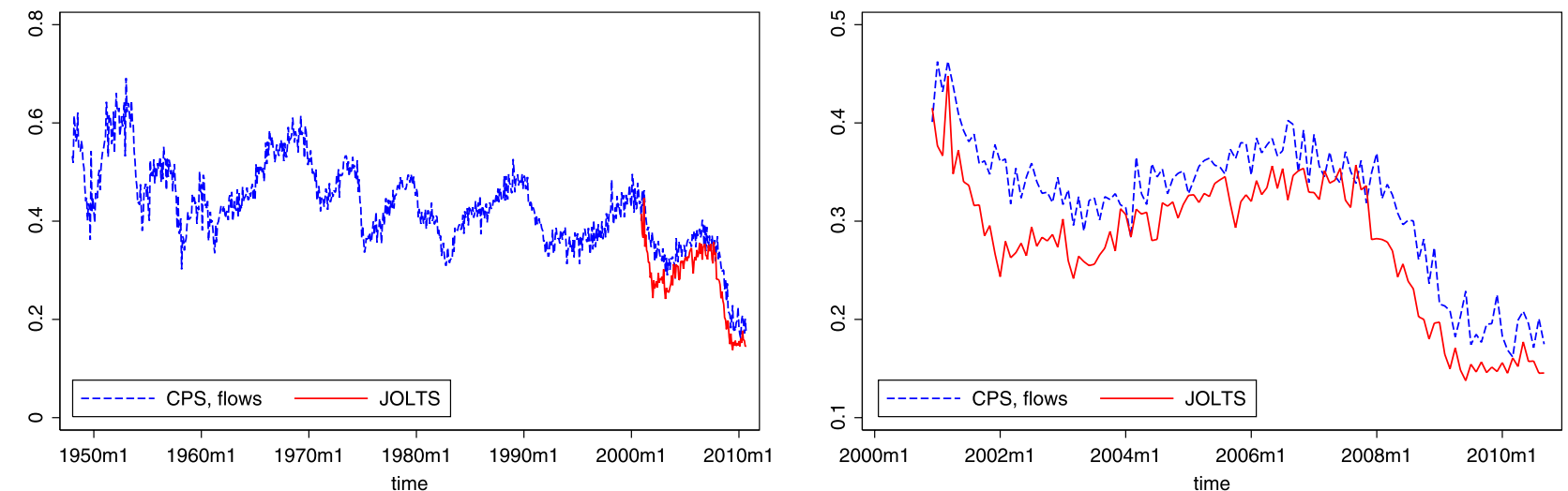

(a) Unemployment exit rate
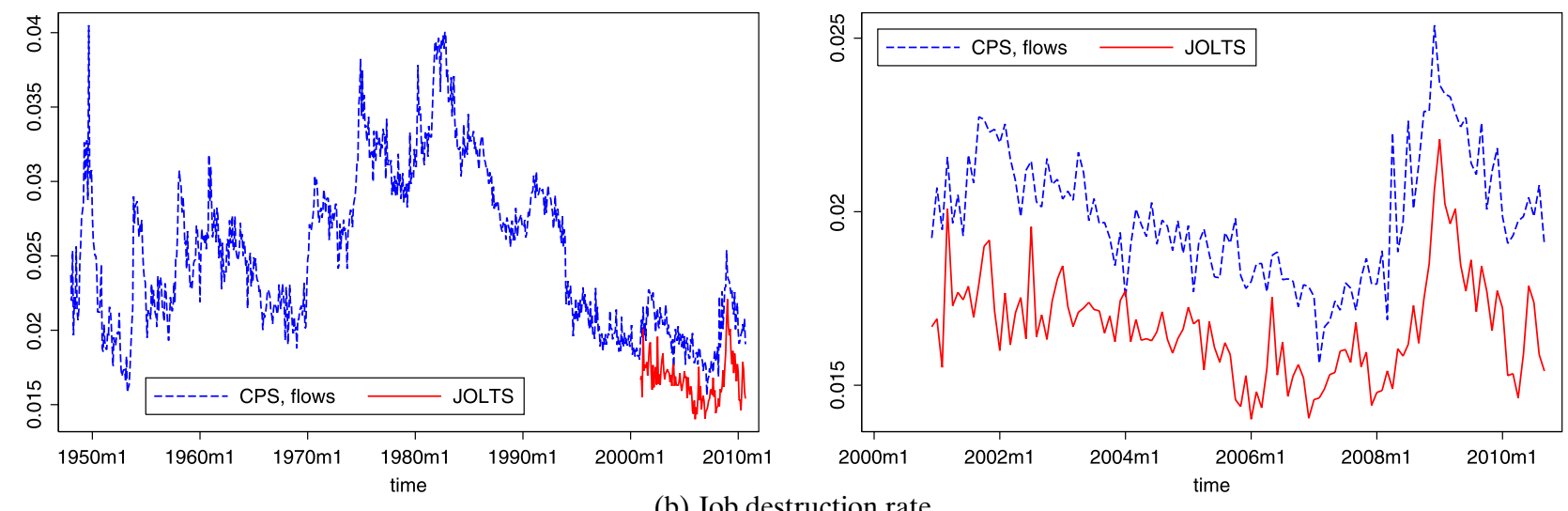

(b) Job destruction rate

FIGURE 1.-CPS versus JOLTS. 


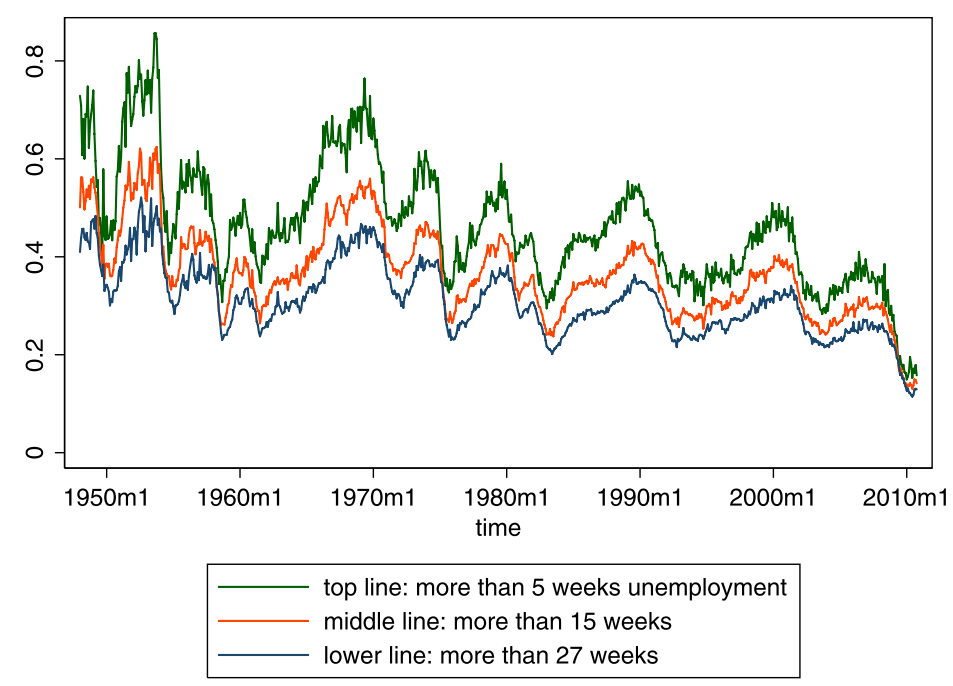

FIGURE 2.-Unemployment exit rate from stocks.

readjusted per person by multiplying by hours and dividing by employment. ${ }^{8}$ These data cover the period 1947q1-2009q1.

Quarterly series of job finding rates and job destruction rates can then be constructed by iterating the law of motion of unemployment at monthly frequency. For example,

$$
\begin{aligned}
u_{t+2} & =s_{t+1}\left(1-u_{t+1}\right)+\left(1-f_{t+1}\right) u_{t+1} \\
& =s_{t+1}+\left[1-s_{t+1}-f_{t+1}\right] u_{t+1} \\
& =s_{t+1}+\left(1-s_{t+1}-f_{t+1}\right)\left[s_{t}+\left(1-s_{t}-f_{t}\right) u_{t}\right] \\
& =s_{t+1}+\left(1-s_{t+1}-f_{t+1}\right) s_{t}+\left(1-s_{t+1}-f_{t+1}\right)\left(1-s_{t}+f_{t}\right) u_{t} .
\end{aligned}
$$

Hence, we calculate

$$
\begin{aligned}
& \bar{s}=F^{2} . s+\left(1-F^{2} . s-F^{2} . f\right) *(F . s+(1-F . s-F . f) * s), \\
& \bar{f}=1-\bar{s}-(1-s-f) *(1-F . s-F . f) *\left(1-F^{2} . s-F^{2} . f\right),
\end{aligned}
$$

where $F^{2}=F$.F. Finally, quarterly series of inflow and outflow rates, as well as quarterly series of employment and unemployment, are obtained by keeping only the first month of each quarter (taking means would reduce the volatility artificially). 
TABLE I

QUARTERLY MOMENTS

\begin{tabular}{lccccc}
\hline \hline & Productivity & $\begin{array}{c}\text { Unempl. } \\
\text { Rate }\end{array}$ & $\begin{array}{c}\text { Unempl. } \\
\text { Exit Rate }\end{array}$ & $\begin{array}{c}\text { Job Destruction } \\
\text { Rate }\end{array}$ & Wage \\
\hline Mean & & 0.058 & 0.785 & 0.0470 & \\
Std & 0.0226 & 0.214 & 0.0784 & 0.163 & 0.0202 \\
Skewness & -0.19 & 0.12 & -0.96 & -0.06 & 0.20 \\
Kurtosis & 3.06 & 2.52 & 5.05 & 2.69 & 3.06 \\
Autocorrelation & 0.91 & 0.95 & 0.94 & 0.91 & 0.96 \\
Corr. with prod. & 1 & -0.51 & 0.43 & -0.54 & 0.74 \\
Corr. with unempl. & -0.51 & 1 & -0.91 & 0.97 & -0.46 \\
Reg. on prod. & 1 & -4.79 & 1.49 & -3.88 & 0.659 \\
Reg. on unempl. & & 1 & -0.33 & 0.74 & \\
\hline
\end{tabular}

aBalanced sample: 1951q1-2010q3. The row labelled "mean" refers to the mean of levels, while the other rows refer to the log of the variable in each column. Row series are HP-filtered with a smoothing parameter of $2.5 e 05$.

The raw data are successively log-transformed, Hodrick-Prescott (HP)filtered, and exponentiated. I use a smoothing parameter of $2.5 e 05$, which is the value that maximizes the correlation between detrended productivity and detrended unemployment. ${ }^{9}$

We think of quarterly transition rates $\bar{s}$ and $\bar{f}$ as data features delivering moments for the model to match. Raw data provide monthly flows that can be time-aggregated at quarterly frequency in a way that preserves the standard law of motion of unemployment rates. The quarterly frequency is dictated by the availability of productivity data and this is why monthly employment series first must be time-aggregated before calculating levels, volatilities, and elasticities.

Table I shows the main moments of the quarterly series. The main difference with respect to Shimer's calculations is the much lower volatility and unemployment elasticity of unemployment outflow rates, contrasting with job destruction rates for which we estimate both higher volatility and elasticity. Notice that, particularly at the quarterly level, $s$ is low and $f$ is large, so a good approximation of the unemployment rate $u=U /(U+E)$ is $s / f .{ }^{10}$ This explains why regressing log unemployment rates on log exit rates and log destruction rates yields an $R^{2}$ of $99 \%$ and coefficients of -0.98 and 0.90 , very close to 1 . Moreover, as $f \simeq s / u$, if $s$ has an unemployment elasticity of 0.7 , then $f$ should have an unemployment elasticity of approximately -0.3 .

The kurtosis is usually close to 3 , which suggests a normal shape for the distribution, except for exit rates, which exhibit more peakedness than the normal.

\footnotetext{
${ }^{9}$ Shimer (2005) used a smoothing parameter of $10^{5}$ instead of the usual 1,600 with quarterly data. I tried to find an objective way to choose the smoothing parameter, and I came very close to Shimer's preferred choice.

${ }^{10} f=1-F . U / U+s E / U \simeq s E / U$ as $F . U \simeq U$. Gross flows in and out of unemployment are large with respect to net flows. Unemployment thus evolves much like a random walk.
} 
TABLE II

CyClical Patterns of INDiVIdual Wage Deciles-Productivity Elasticity, AND VOLATILITY ${ }^{\mathrm{a}}$

\begin{tabular}{lcccccccc}
\hline \hline & \multicolumn{2}{c}{ Males } & & \multicolumn{2}{c}{ Females } & & \multicolumn{2}{c}{ All } \\
\cline { 2 - 3 } & Elasticity & Volatility & & Elasticity & Volatility & & Elasticity & Volatility \\
\hline P100 & 0.42 & 0.016 & & 0.36 & 0.015 & & 0.43 & 0.029 \\
P90 & 0.35 & 0.012 & & 0.30 & 0.010 & & 0.44 & 0.013 \\
P80 & 0.33 & 0.011 & & 0.30 & 0.010 & & 0.41 & 0.011 \\
P70 & 0.31 & 0.012 & & 0.36 & 0.010 & & 0.43 & 0.013 \\
P60 & 0.37 & 0.013 & & 0.43 & 0.012 & & 0.51 & 0.014 \\
P50 & 0.41 & 0.015 & & 0.43 & 0.012 & & 0.54 & 0.015 \\
P40 & 0.50 & 0.018 & & 0.52 & 0.014 & & 0.63 & 0.018 \\
P30 & 0.62 & 0.020 & & 0.54 & 0.016 & & 0.67 & 0.020 \\
P20 & 0.69 & 0.025 & & 0.60 & 0.019 & & 0.76 & 0.023 \\
P10 & 0.92 & 0.033 & & 0.64 & 0.032 & & 0.85 & 0.032 \\
\hline
\end{tabular}

\footnotetext{
a Wage deciles were calculated by Heathcote, Perri, and Violante (2010) from CPS, 1967-2005. Available at http:// www.economicdynamics.org/RED-cross-sectional-facts.htm. The log of each wage decile was detrended using a linear trend before being regressed on log aggregate productivity (BLS series PS85006163). The volatility is the standard deviation of detrended deciles.
}

This together with the negative skewness indicates a certain propensity for exit rates to take "abnormally" low values.

The estimated elasticity of wages to productivity is close to (yet higher than) that calculated by Gertler and Trigari (2009) from CPS data (series posterior to 1967).

\subsection{Wage Inequality}

I use the data on wage (per hour) inequality constructed by Heathcote, Perri, and Violante (2010) from the series of CPS surveys, available from the website of the Review of Economic Dynamics, to calculate the volatilities and productivity elasticities of wage deciles. In practice, I regress the log of each wage decile on a linear trend and log productivity (mean per year). Table II shows that both volatilities and elasticities are definitely decreasing in rank until about the 6th or 7 th decile, and are then approximately constant or moderately increasing above the 7 th decile. Figure 3 displays detrended wage deciles over time.

\section{PARAMETRIC SPECIFICATION AND ESTIMATION}

\subsection{Parametrization}

\subsubsection{The Aggregate Productivity Process}

Let $F$ denote the equilibrium distribution of $y_{t}$. Let $C$ denote a parametric copula. Let $a_{1}<\cdots<a_{N}$ define a grid on $[\varepsilon, 1-\varepsilon] \subset(0,1)$ of $N$ linearly spaced points including end points $\varepsilon$ and $1-\varepsilon$. Then $y_{i}=F^{-1}\left(a_{i}\right)$ and 


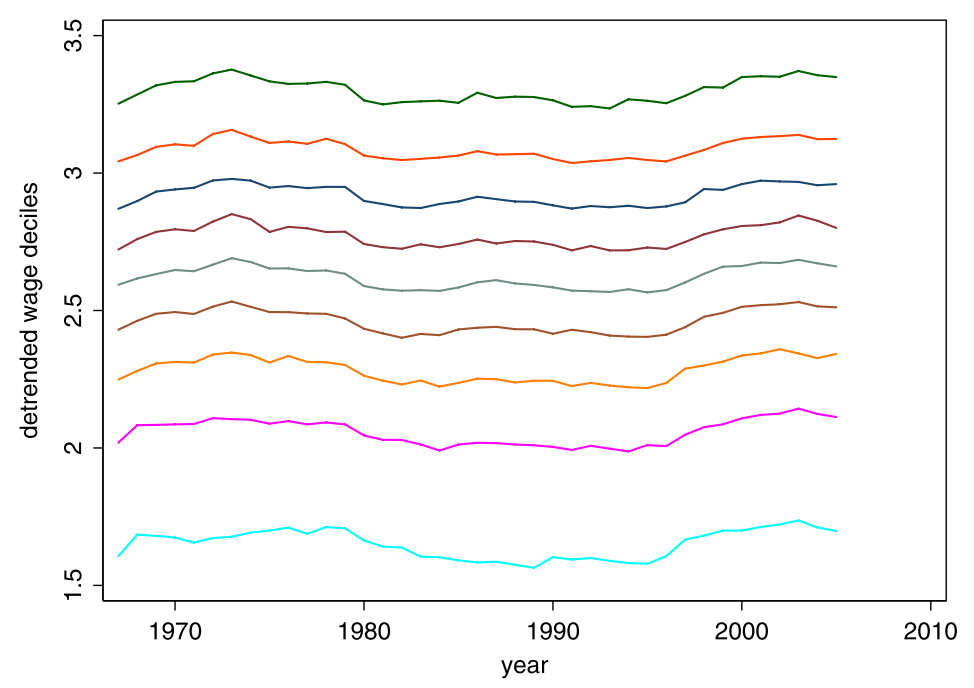

FIGURE 3.-Dynamics of Detrended Wage Deciles D1-D9. Source: CPS, 1967-2005 and Heathcote, Perri, and Violante (2010).

$\pi_{i j} \propto c\left(a_{i}, a_{j}\right)$, where $c$ denotes the copula density and with the normalization $\sum_{j} \pi_{i j}=1$. In practice, I use $N=100$ and $\varepsilon=0.002 ; F$ is a log-normal distribution with parameters 0 and $\sigma$, and $c$ is a Gaussian copula density with parameter $\rho$.

This may look like a rather convoluted way to define a Gaussian AR(1) process, but it has the advantage of potentially allowing for independent changes in the specifications for the marginal distribution $F$ and the stochastic process of ranks $c$. For example, it might prove useful in some cases to use a student copula or a marginal distribution with fatter tails than the normal. Moreover, it is a simple way to construct a Markov chain.

\subsubsection{Worker Heterogeneity}

I specify match productivity as $y_{i}(m)=y_{i} x_{m}$, where $x_{m}, m=1, \ldots, M$, is a grid of $M$ linearly spaced points on $[\underline{x}, \underline{x}+1]$. The choice of the support does not matter much (provided it is large enough and contains one) if the distribution of ability within that support is general enough. I assume a beta distribution, namely

$$
\ell_{m}=\operatorname{betapdf}\left(x_{m}-\underline{x}, \eta, \mu\right)
$$

with the normalization $\sum_{m} \ell_{m}=1$. The beta distribution allows for a variety of shapes for the density (increasing, decreasing, nonmonotone, concave, or convex). I will use a very dense grid of $M=500$ points to guarantee a good resolution in the left tail. 
Note that aggregate productivity is the mean of $y_{t}(m)$ across all $m$ such that $S_{t}(m)>0$ :

$$
\begin{aligned}
\bar{y}_{t} & =\frac{\sum_{m}\left(1-u_{t}(m)\right) \ell_{m} y_{t}(m) \mathbf{1}\left\{S_{t}(m)>0\right\}}{1-u_{t}} \\
& =\frac{\sum_{m}\left(1-u_{t}(m)\right) \ell_{m}\left(\underline{x}+x_{m}\right) \mathbf{1}\left\{S_{t}(m)>0\right\}}{1-u_{t}} y_{t} \\
& =\bar{x}_{t} y_{t} \quad \text { (say). }
\end{aligned}
$$

The dynamics of $\bar{y}_{t}$ differs from the dynamics of $y_{t}$ if composition effects make $\bar{x}_{t}$, the mean ability of employees, differ from the mean ability of all workers, employed and unemployed. In practice, only a small fraction of workers face nonparticipation risk and therefore $\bar{x}_{m}$ does not differ much from the unconditional mean.

\subsubsection{Opportunity Cost of Employment}

Last, the opportunity cost of employment (leisure utility, UI benefits, etc.) is specified as $z_{i}(m)=z_{0}+\alpha\left[y_{i}(m)-z_{0}\right]$. I allow for a potential indexation of unemployment flow utility on productivity. Otherwise the reservation wage of high-skill workers is lower in booms than in busts as unemployed workers face better future prospects in booms than in busts. Also, if $\alpha$ is low, high-skill workers have lower reservation wages than low-skill workers, for exactly the same reason.

Note that $\alpha$ is not identified from employment and turnover data. As $y_{i}(m)-$ $z_{i}(m)=\alpha\left[y_{i}(m)-z_{0}\right]$, changing $\alpha$ into $\alpha^{\prime}$ changes $S_{i}(m)$ into $\frac{\alpha^{\prime}}{\alpha} S_{i}(m)$ without changing unemployment rates and composition.

\subsubsection{Estimation/Calibration}

I set the unit of time equal to a quarter. The parameters to be estimated are the turnover parameters $\lambda_{0}, \lambda_{1}$, and $\delta$, the probability of moving upon receiving an outside offer $\tau$, the leisure cost parameters $z_{0}$ and $\alpha$, and parameters $\underline{x}, \eta$, and $\mu$ of the distribution of heterogeneity. These parameters will be calibrated so as to fit unemployment, turnover, and wage dynamics as I now explain.

Using results in Jolivet, Postel-Vinay, and Robin (2006), I estimate the proportion of employees' contacts with alternative employers resulting in actual mobility to $53 \%$. I thus set $\tau=0.5$. The model predicts a job-to-job mobility rate $q_{t}$ such that $q_{t}=\tau \lambda_{1}\left(1-s_{t}\right)$. Using JOLTS data, an on-the-job offer arrival rate of $\lambda_{1}=0.12 \times \lambda_{0}$ can be calculated.

For a given normalization of $\alpha$, the remaining parameters $\left(\lambda_{0}, \delta, \underline{x}, \eta, \mu, z_{0}\right)$ are estimated by simulating very long series of $T=10,000$ observations so as to match the following moments: 
- The mean productivity is 1 , the standard deviation of $\log$ productivity is equal to 0.0223 , and its autocorrelation is 0.91 .

- The mean unemployment rate is $5.8 \%$, the standard deviation of log unemployment is 0.214 , and its kurtosis is 2.52 .

- The mean exit rate from unemployment is $78.5 \%$.

I purposely do not use any wage information. Thus one can determine how much of the observed wage patterns the model can reproduce without programming the model to fit them beforehand. In a second step, a value for $\alpha$ is selected so as to fit the elasticity of wages to productivity.

\section{ESTIMATES AND FIT}

\subsection{Parameter Estimates and Fit of Moments}

The GMM criterion exhibits many local optima and it was necessary to try many initial values to find that $z_{0}=0.77, \sigma=0.023, \rho=0.94, \lambda_{0}=0.99, s=$ $0.042, \underline{x}=0.73, \eta=2.00$, and $\mu=5.56$ are values of the structural parameters that best match the empirical moments. Then $\alpha=0.64$ is found to match the elasticity of aggregate wages optimally.

Table III displays the simulated moments using these parameter values. The model manages very well to amplify productivity shocks. The elasticity of unemployment to productivity is too high, but that is expected in a model with only one exogenous source of shocks. The job destruction rate is not volatile enough and the exit rate from unemployment is too volatile. The job destruction rate also exhibits too much excess kurtosis.

TABLE III

FIT OF EMPLOYMENT AND TURNOVER MOMENTS ${ }^{\mathrm{a}}$

\begin{tabular}{lccccc}
\hline \hline & Productivity & $\begin{array}{c}\text { Unempl. } \\
\text { Rate }\end{array}$ & $\begin{array}{c}\text { Unempl. } \\
\text { Exit Rate }\end{array}$ & $\begin{array}{c}\text { Job Destruction } \\
\text { Rate }\end{array}$ & Wage \\
\hline Mean & 1 & 0.057 & 0.753 & 0.0435 & 0.932 \\
Std & 0.022 & 0.213 & 0.220 & 0.0573 & 0.0153 \\
Skewness & -0.10 & 0.69 & -0.96 & 2.27 & 0.085 \\
Kurtosis & 3.33 & 3.20 & 4.30 & 10.81 & 3.81 \\
Autocorrelation & 0.93 & 0.94 & 0.95 & 0.02 & 0.99 \\
Corr. with prod. & 1 & -0.97 & 0.94 & -0.31 & 0.93 \\
Corr. with unempl. & -0.97 & 1 & -0.98 & 0.27 & -0.92 \\
Reg. on prod. & 1 & -9.47 & 9.45 & -0.81 & 0.659 \\
Reg. on unempl. & & 1 & -0.99 & 0.0023 & \\
\hline
\end{tabular}

\footnotetext{
aThe rows labelled "mean" refer to the mean of levels, while the other rows refer to the log of the variable in each column. These moments were calculated from a simulation of 10,000 observations.
} 


\subsection{Worker Heterogeneity}

Figure 4 shows the distribution of worker heterogeneity and how it affects individual productivity given the state of the economy. Every dotted line in panel (a) of the figure corresponds to a different ability type. The thick line in the middle is the 45-degree line and IT corresponds to the productivity of a worker of ability 1 . The other thick line at the bottom indicates the viability threshold: for a given aggregate state $i$, all individual types $m$ such that $S_{i}(m) \leq 0$ have their productivity below the threshold. Only a small fraction, about $6 \%$, of all workers bear the risk of endogenous layoff. Panel (b) displays the distributions of worker types in the whole population and in the subpopulation of unemployed workers. As expected, low ability workers are overrepresented among the unemployed.

Figure 5, panel (a) displays the actual unemployment rates within various education groups as a function of the overall unemployment rate (all workers, 25 years and over; 1992m1-2010m10). There is a clear linear relationship, which implies that the composition of unemployment by education should remain stable over time if the composition of the labor force did not change, which is not true. Notice also that less educated workers face a higher risk of unemployment. Panel (b) shows the unemployment rate over time, ${ }^{11}$ as a function of the aggregate unemployment rate, for various subpopulations of lowskill workers $(25 \%, 50 \%$ and $90 \%$, most unskilled). The same linear relationship emerges, which favors the following possible interpretation of the actual pattern by education: The proportion of low-skill workers at risk of nonparticipation via a productivity shock annihilating the surplus is just simply higher among low-education workers.

\subsection{The Amplification Mechanism}

The mechanism that amplifies productivity shocks is simple to understand. In a boom, unemployment is steady and all separations follow from exogenous shocks. When aggregate productivity falls more workers lose their jobs as more match surpluses become negative (see Figure 6). About 4\% unemployment accrues because of the $4.2 \%$ exogenous layoff rate. One may call this minimum unemployment level frictional unemployment. Unemployment due to business-cycle conditions ranges between 0 and $6 \%$ depending on the severity of the recession. Note that the correlation between unemployment rates and productivity shocks is high, because the link shown in Figure 6 is smooth and monotone. A smaller correlation requires more nonlinearity that can be obtained by reducing the aggregate productivity threshold that triggers endogenous layoff.

The mean leisure cost $z_{t}(m)$ averaged over worker types and time is 0.86 , somewhere between Hagedorn and Manovskii's (2008) 0.95 calibration, and

\footnotetext{
${ }^{11}$ Straight lines are obtained in both the steady-state and the out-of-equilibrium simulations.
} 


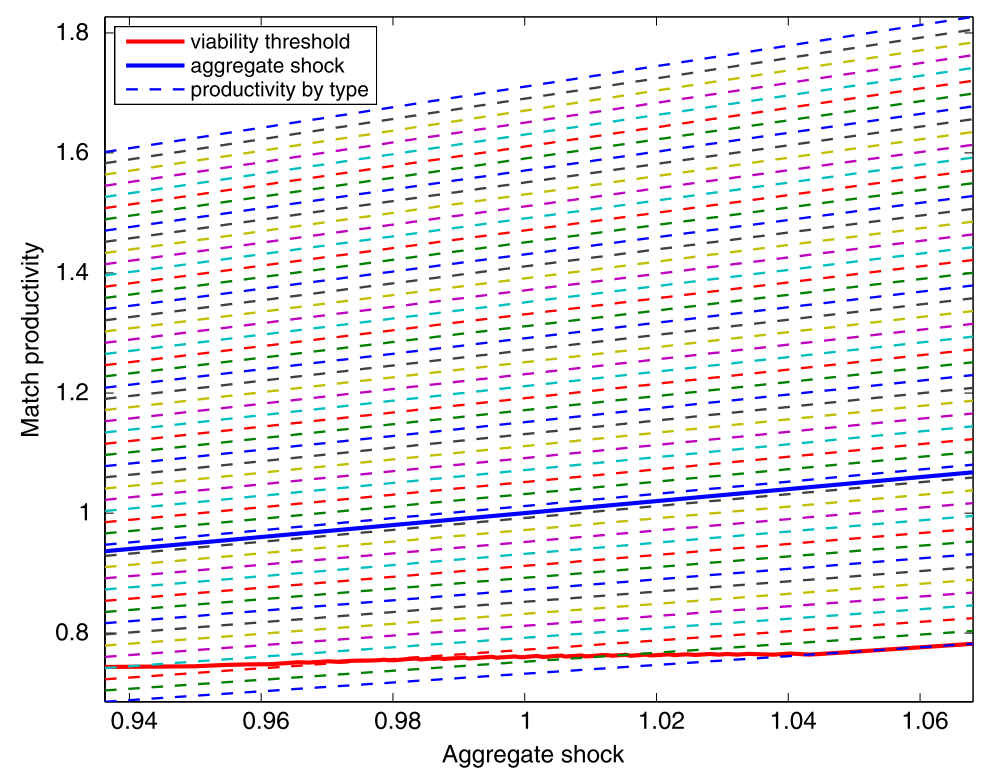

(a) Match productivity

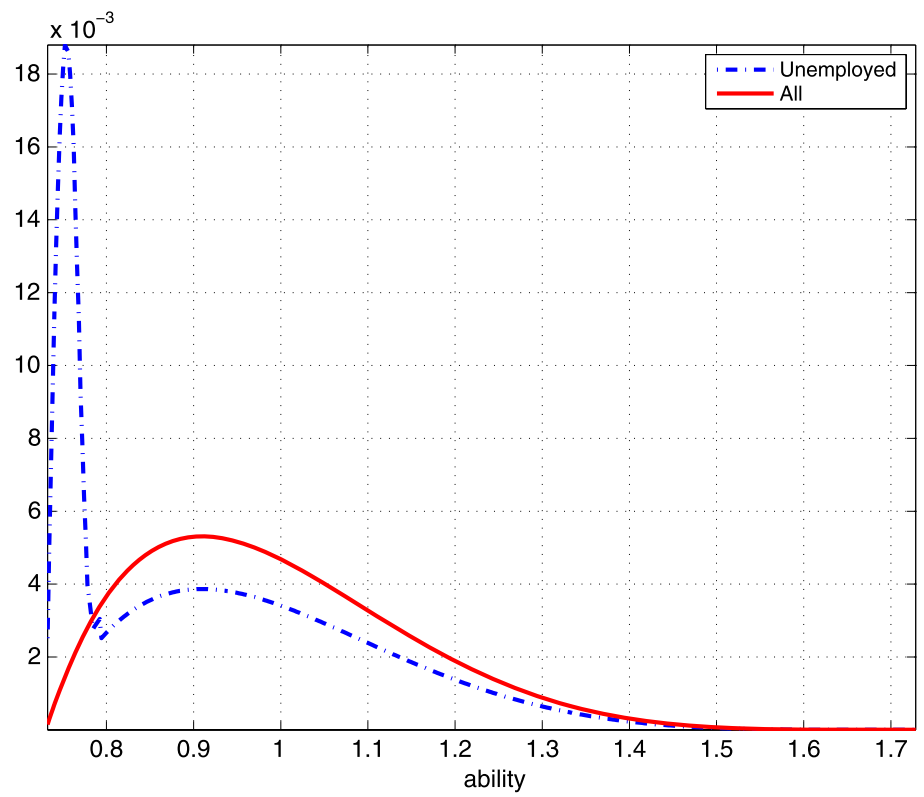

(b) Distribution of types

FIGURE 4.-Heterogeneous productivity. 


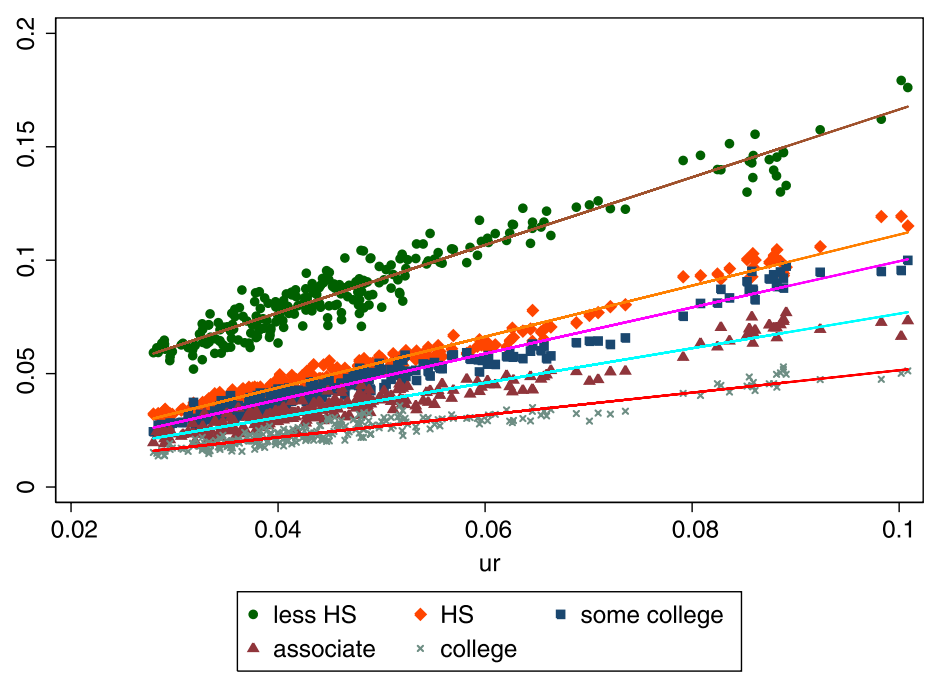

(a) Unemployment rate by education (CPS)

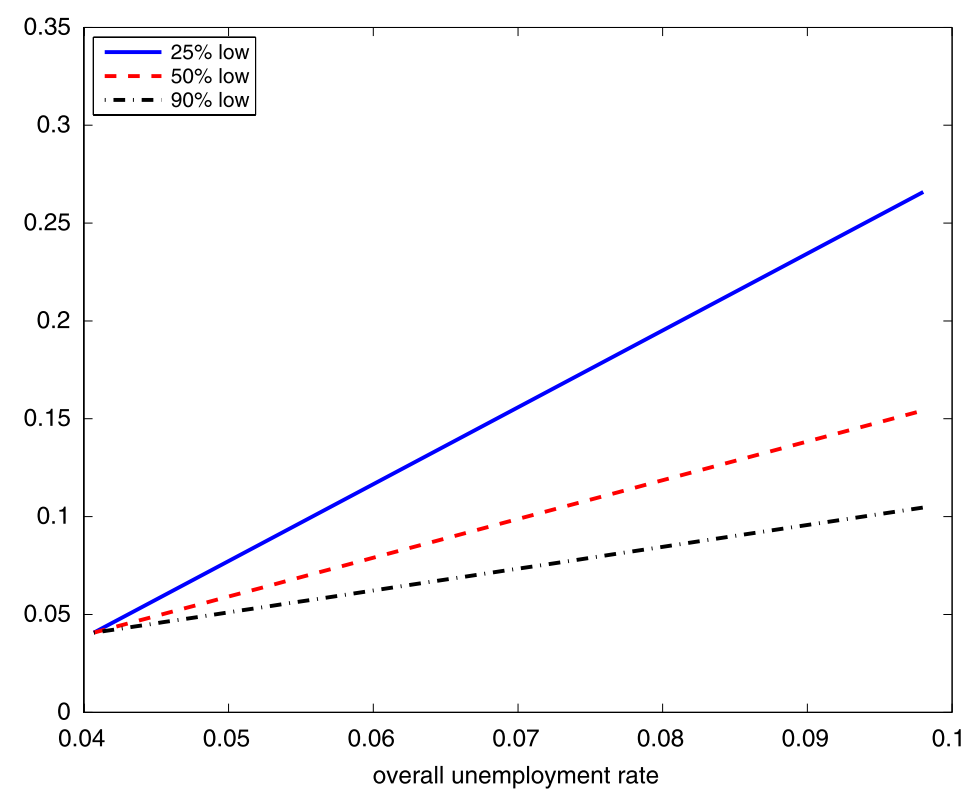

(b) Unemployment rate among various low-skill groups (model's prediction)

FIGURE 5.-Composition of unemployment.

Hall and Milgrom's 0.70 (2008). Workers in the low range of abilities have a mean unemployment benefit/productivity ratio close to 1 , whereas high productivity workers have one that is closer to 0.70 (see Figure 7). The ability of 


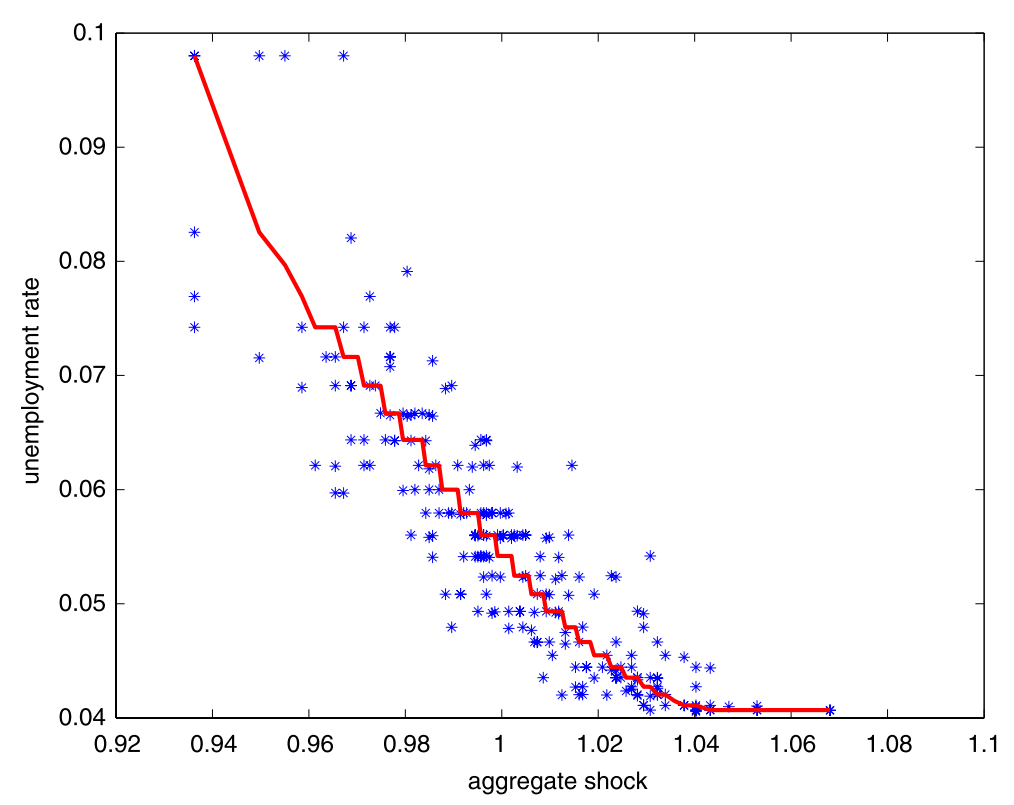

FIGURE 6.-Unemployment rate as a function of the aggregate shock. For each step down, a new group of low ability workers becomes employable as aggregate productivity rises. When the aggregate productivity index reaches about 1.04, all workers have positive surplus. The unemployment rate does not quite jump to its state-contingent equilibrium value (continuous line), but scatters around it, as the dots, corresponding to one simulation, indicate.

the model to match the volatilities of aggregate productivity and unemployment depends on there being a small fraction of workers at risk of endogenous job destruction. So, the argument of this paper does not contradict the small surplus argument of Hagedorn and Manovskii. However, with heterogeneous workers, not all workers need to face the same small surplus and not at all times.

\subsection{Fit of Main Series}

Given parameter estimates, I filter out aggregate productivity shocks $y_{t}$ so as to minimize $\left(Y_{t}-\bar{x}_{t} y_{t}\right)^{2}$ for all $t$, where $Y_{t}$ denotes observed productivity and where $\bar{x}_{t}=\frac{\sum_{m}\left(1-u_{t}(m)\right) \ell_{m}\left(\underline{x}+x_{m}\right) \mathbf{1}\left\{S_{t}(m)>0\right\}}{1-u_{t}}$ depends on $y_{t}$ via the sign of $S_{t}(m) .{ }^{12}$ A dynamic simulation consists of implementing the model's law of motions for unemployment and wage distributions driven by aggregate productivity shocks. With $N=100$ and $M=500$, I thus keep track of $10^{5}$ separate trajecto-

\footnotetext{
${ }^{12}$ For all periods, I could find a value of $y_{t}$ such that the predicted aggregate productivity is essentially indistinguishable from the actual one.
} 


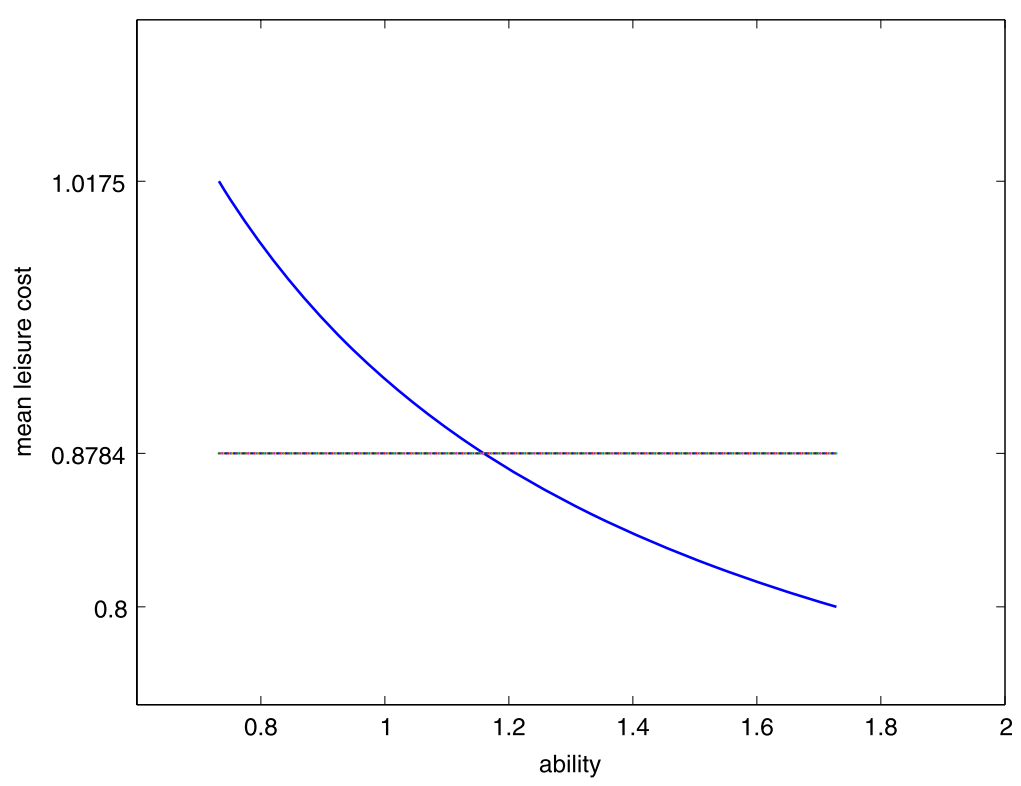

FIGURE 7.-Mean unemployment benefit/output ratio $\left(z_{t}(m) / y_{t}(m)\right)$ by ability.

ries $(2 N M)$. This is a lot but well within the possibilities of modern laptops. ${ }^{13}$ A few seconds suffice to make these calculations. Estimation was less demanding, as only employment and turnover had to be simulated. A few minutes were enough to reach convergence.

Figure 8 displays the predicted series of unemployment rates, (assuming revelation of $y_{t}$ at the beginning of each period), unemployment exit rates, job destruction rates, and aggregate wages. The overall $R^{2}$ coefficients are, respectively, $27.8 \%, 18.8 \%, 2.6 \%$, and $43.8 \%$. For the period 1948-1990, the fit is much better: $45.0 \%, 37.1 \%, 3.7 \%$, and $56.3 \%$. After 1990, obviously, other factors intervene to decouple unemployment, turnover, and wages from productivity shocks.

These model fit measures are more informative than traditional impulseresponse functions. In an economy that never reaches a steady-state equilibrium, they tell us how good the model is at capturing the directional changes of endogenous variables following the continuous flow of macroeconomic shocks. Of course, with many latent sources of exogenous shocks, given the nonlinear channels of their effects on endogenous outcomes in DGSE models, it may prove more difficult to filter out exogenous innovations.

The model does not capture the dynamics of job destruction rates very well. The predicted dynamics is not smooth enough compared to the true one. This

\footnotetext{
${ }^{13}$ I use standard MacBooks and Matlab.
} 


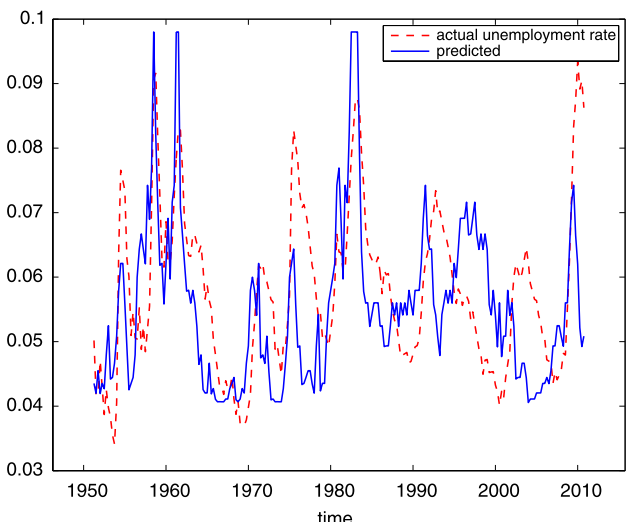

(a) Unemployment

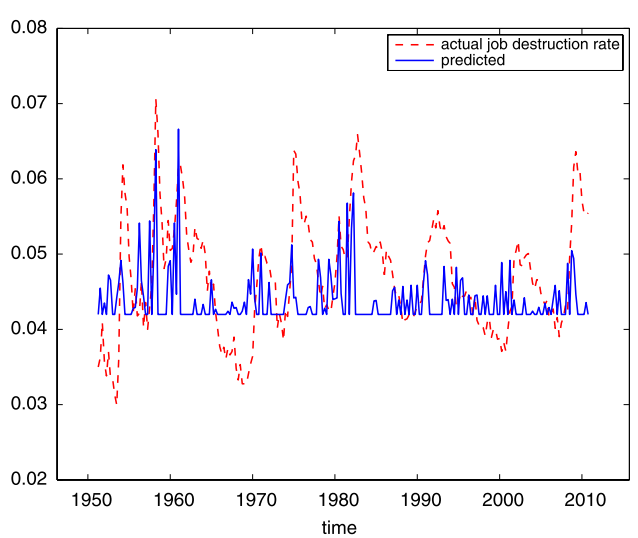

(c) Job destruction rate

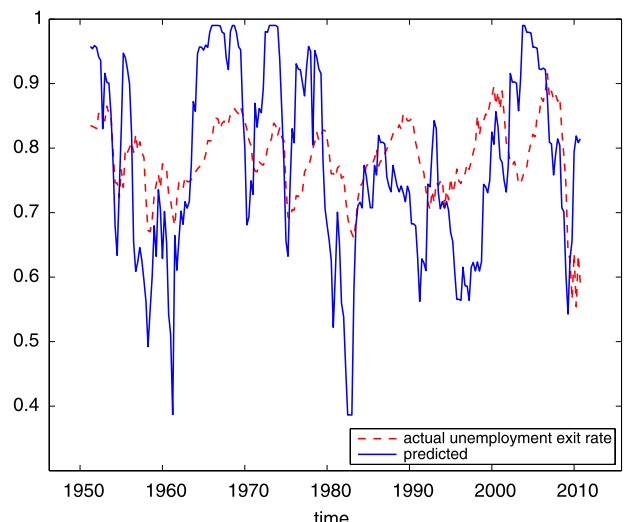

(b) Unemployment exit rate

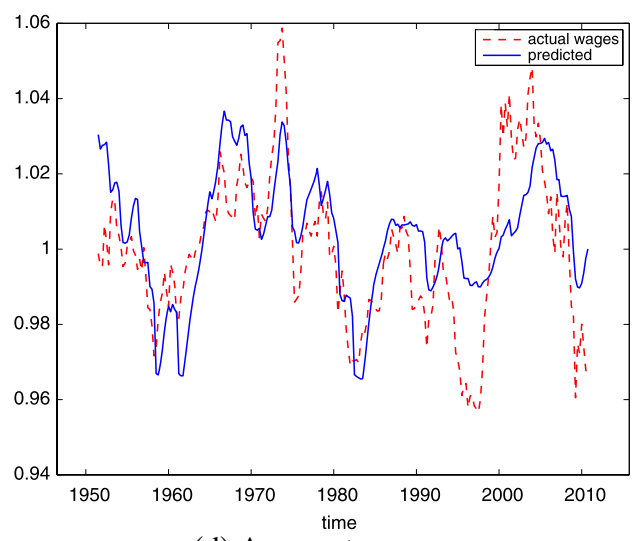

(d) Aggregate wages

FIGURE 8.-Prediction of unemployment, turnover, and wages. 
absence of smoothness could already be seen from the overestimated kurtosis (11 instead of the normal 3). The unemployment exit rate is also too volatile.

It is worth emphasizing at this point the strikingly good prediction of aggregate wages. Note that it is not very sensitive to the choice of $\alpha$, the only parameter that was not estimated from turnover data. ${ }^{14}$ For comparison, note that regressing log wages on log productivity yields an $R^{2}$ of $54 \%$ (the square of the correlation).

\subsection{Wage Inequality Dynamics}

Last, let us turn to wage distribution dynamics. Figure 9 shows how predicted wage deciles change over time. The average interdecile ratios D9/D5 and D5/D1 are around 2 (2.05 and 2.20) in the data. They are close to 1.2 (1.29 and 1.23) in the simulation. There is thus room for additional sources of wage dispersion, yet the model already generates a fair amount of inequality. As in the data, extreme deciles are more elastic and volatile than intermediate ones; a minimum is attained somewhere between the second and third deciles (see Table IV). This is because the lower part of the distribution essentially comprises starting wages, whereas the upper part of the wage distribution es-

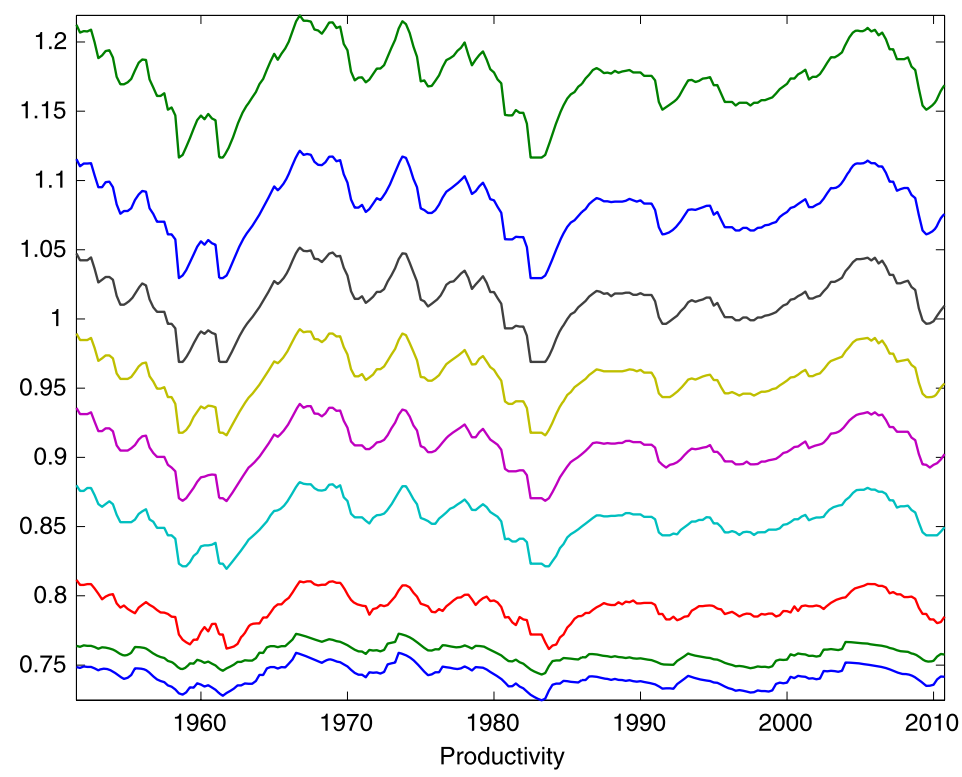

FIGURE 9.-Dynamics of wage deciles (simulated using filtered productivity shocks).

${ }^{14}$ With $\alpha=0.4$, I obtain an $R^{2}$ of $40 \%$ (53\% after 1990); with $\alpha=0.75$, I get $45 \%$ and $58 \%$. 
TABLE IV

FIT OF CYCLICAL PATTERNS OF INDIVIDUAL WAGE DECILES (CALCULATED FROM A SIMULATION OF 10,000 OBSERVATIONS)

\begin{tabular}{lccccc}
\hline \hline & \multicolumn{2}{c}{ Actual (Males) } & & \multicolumn{2}{c}{ Simulated } \\
\cline { 2 - 3 } \cline { 5 - 6 } & Elasticity & Volatility & & Elasticity & Volatility \\
\hline P90 & 0.35 & 0.012 & & 0.83 & 0.0191 \\
P80 & 0.33 & 0.011 & & 0.80 & 0.0186 \\
P70 & 0.31 & 0.012 & & 0.78 & 0.0181 \\
P60 & 0.37 & 0.013 & & 0.74 & 0.0175 \\
P50 & 0.41 & 0.015 & & 0.71 & 0.0169 \\
P40 & 0.50 & 0.018 & & 0.65 & 0.0156 \\
P30 & 0.62 & 0.020 & & 0.46 & 0.0122 \\
P20 & 0.69 & 0.025 & & 0.31 & 0.0070 \\
P10 & 0.92 & 0.033 & 0.35 & 0.0081 \\
\hline
\end{tabular}

sentially comprises promotion wages. ${ }^{15}$ Moreover, the most able individuals exhibit both the lowest starting wages and the highest promotion wages (see Figure 10). This is inherent to the nature of search models: higher future prospects

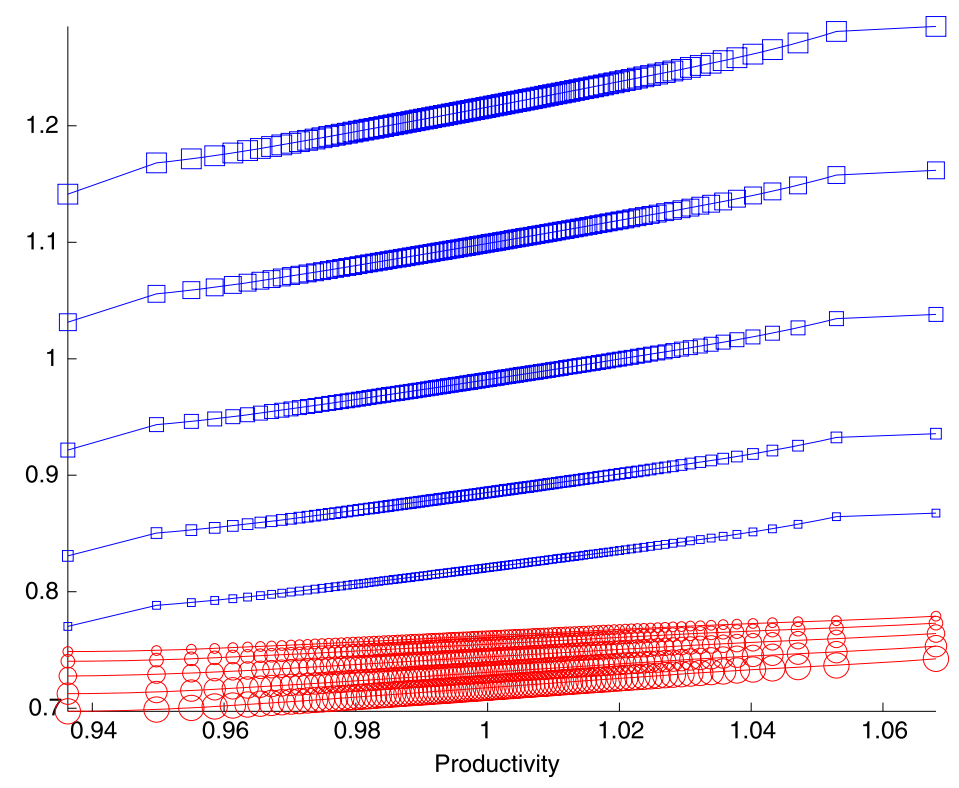

FIGURE 10.-Starting wages (circles) and promotion wages (squares) for various ability quantiles $(1 / 10,1 / 4,1 / 2,3 / 4,9 / 10)$. The size of the symbol is proportional to ability rank.

${ }^{15}$ There may be overlapping due to wage rigidities. 
generate lower reservation wages..$^{16}$ At the same time, high ability workers face higher wage elasticity with respect to aggregate productivity shocks (thanks to the complementarity between $x$ and $y$ in match productivity).

Notice that long term contracts tend to attenuate the volatility of individual wage contracts. A worker who obtains a promotion because she managed to make her employer compete with another firm will not obtain any additional wage rise if the economy booms, unless she finds another would-be employer. A similar reasoning applies to workers paid their reservation wage. On the other hand, wage rises are expected to be bigger in a boom than in a bust.

To quantify how much wage inequality is generated by worker heterogeneity and how much is left to individual wage dynamics, I next consider the following variance decomposition exercise. Let $w_{i t}$ denote the wage of an individual $i$ at time $t$ and let $z_{i t}$ denote some characteristics. Then

$$
\operatorname{Var} w_{i t}=\underbrace{\operatorname{Var} \mathbb{E}\left(w_{i t} \mid z_{i t}\right)}_{\text {between }}+\underbrace{\mathbb{E} \operatorname{Var}\left(w_{i t} \mid z_{i t}\right)}_{\text {within }} .
$$

I find that about a third of the cross-sectional wage variance can be explained by ability difference (see Figure 11). This is a bit low compared to available estimates, yet of a similar order of magnitude. Abowd, Creecy, and Kramarz

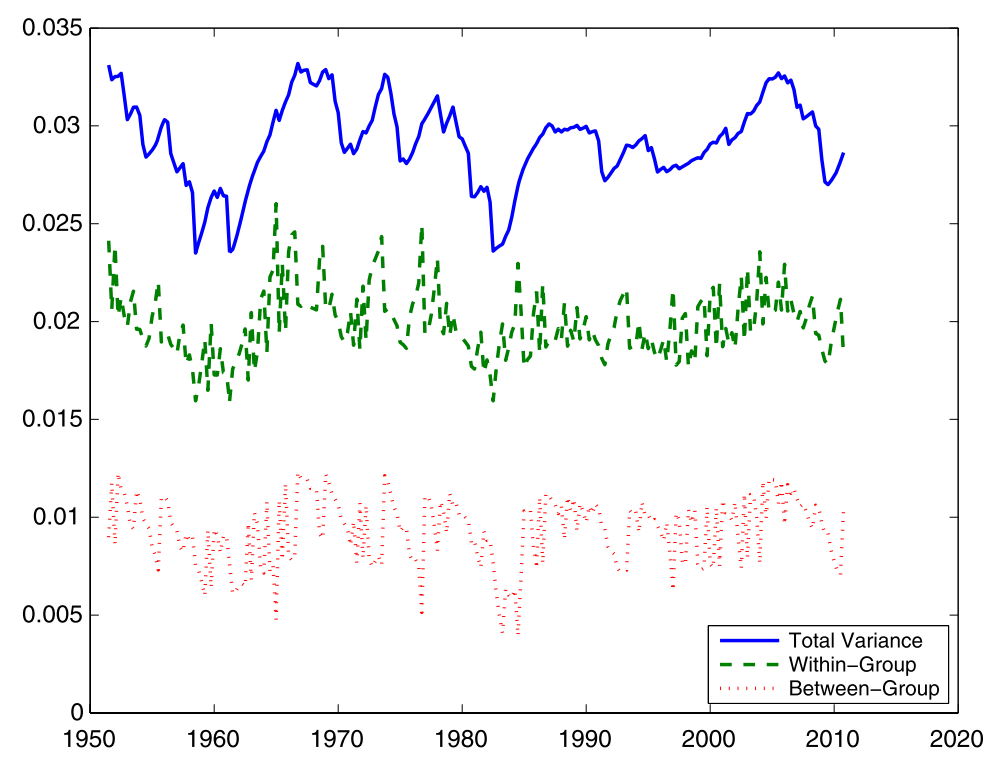

FIGURE 11.-Wage variance decomposition.

\footnotetext{
${ }^{16}$ This is not true if the utility of leisure is sufficiently increasing in worker ability (via the dependence to match productivity).
} 
(2002) thus estimated a $46 \%$ contribution (covariance divided by total variance) of person effects using the State of Washington UI data. ${ }^{17}$

\section{CONCLUSION}

We have proposed a simple dynamic search-matching model with crosssectional wage dispersion and worker heterogeneous abilities. Worker heterogeneity interacts with aggregate shocks to match productivity in a way that allows for endogenous job destruction. It suffices that a small fraction of the total workforce be at risk of a shock to productivity that renders the match surplus negative to amplify productivity shocks enough to generate the observed unemployment volatility. Moreover, we show that the model can generate sizeable cross-sectional wage inequality and with a dynamic that is similar to the observed pattern: wages in the middle of the distribution are less procyclical than wages in the bottom and the top.

Our prototypical model is extremely simple to simulate outside the steadystate equilibrium and still generates very rich dynamics. This is due to two very strong assumptions: firms have full monopsony power and they are identical. Giving workers some bargaining power as in Cahuc, Postel-Vinay, and Robin (2006) and Dey and Flinn (2005), and allowing for firm heterogeneity as in Lise, Meghir, and Robin (2009), in a macrodynamic model, are very exciting avenues for further research.

\section{REFERENCES}

Abowd, J. M., R. H. CReecy, and F. Kramarz (2002): "Computing Person and Firm Effects Using Linked Longitudinal Employer-Employee Data,” Technical Paper 2002-06, Longitudinal Employer-Household Dynamics, Center for Economic Studies, U.S. Census Bureau. $[1353,1354]$

CAHUC, P., F. Postel-VinaY, AND J.-M. Robin (2006): "Wage Bargaining With On-the-Job Search: Theory and Evidence," Econometrica, 74, 323-364. [1354]

DEY, M. S., AND C. J. FLINN (2005): "An Equilibrium Model of Health Insurance Provision and Wage Determination," Econometrica, 73, 571-627. [1354]

Gertler, M., AND A. Trigari (2009): "Unemployment Fluctuations With Staggered Nash Wage Bargaining," Journal of Political Economy, 117, 38-86. [1329,1341]

HAGEDORN, M., AND I. MANOVSKII (2008): “The Cyclical Behavior of Equilibrium Unemployment and Vacancies Revisited," American Economic Review, 98, 1692-1706. [1329,1345]

HALL, R. E. (2005): "Job Loss, Job Finding, and Unemployment in the U.S. Economy Over the Past Fifty Years," in NBER Macroeconomics Annual 2005, ed. by M. Gertler and K. Rogoff. Cambridge, MA: MIT Press, 103-137. [1329]

HALl, R. E., AND A. B. KRUEGER (2010): "Evidence on the Determinants of the Choice Between Wage Posting and Wage Bargaining,” Working Paper 16033, NBER. [1328]

HALL, R. E., AND P. R. MiLGROM (2008): "The Limited Influence of Unemployment on the Wage Bargain," American Economic Review, 98, 1653-1674. [1329,1347]

\footnotetext{
${ }^{17}$ They estimated about $47 \%$ for firm effects and $27 \%$ for residuals. This does not sum to 1 because of correlations between factors.
} 
Heathcote, J., F. Perri, and G. L. Violante (2010): "Unequal We Stand: An Empirical Analysis of Economic Inequality in the United States: 1967-2006," Review of Economic Dynamics, 13, 15-51. [1341,1342]

Jolivet, G., F. Postel-VinaY, AND J.-M. Robin (2006): "The Empirical Content of the Job Search Model: Labor Mobility and Wage Distributions in Europe and the US," European Economic Review, 50, 877-907. [1343]

Lise, J., C. MeghiR, AND J.-M. Robin (2009): “Matching, Sorting and Wages,” Discussion Paper, University College London. [1328,1354]

MACLEOD, W. B., AND J. M. MALCOMSON (1993): "Investments, Holdup, and the Form of Market Contracts," American Economic Review, 83, 811-837. [1333]

MenZIO, G., AND S. SHI (2009): "Efficient Search on the Job and the Business Cycle," Discussion Paper 14905, NBER. [1328]

_ (2010a): "Block Recursive Equilibria for Stochastic Models of Search on the Job," Journal of Economic Theory, 145, 1453-1494. [1328]

_ (2010b): "Directed Search on the Job, Heterogeneity, and Aggregate Fluctuations," American Economic Review, 100, 327-332. [1328]

MoRTENSEN, D., AND E. NAGYPÁL (2007): “More on Unemployment and Vacancy Fluctuations," Review of Economic Dynamics, 10, 327-347. [1329]

MorTEnSEn, D. T. (2005): Wage Dispersion. Why Are Similar Workers Paid Differently? Cambridge, MA: MIT Press. [1327]

Mortensen, D. T., AND C. A. Pissarides (1994): "Job Creation and Job Destruction in the Theory of Unemployment,” The Review of Economic Studies, 61, 397-415. [1327,1329]

MosCARINI, G., AND F. POSTEL-VINAY (2008): "The Timing of Labor Market Expansions: New Facts and a New Hypothesis," in NBER Macroeconomics Annual 2008. University of Chicago Press. [1327]

(2009): “Large Employers Are More Cyclically Sensitive,” Working Paper 14740, NBER. [1327]

PISSARIDES, C. A. (2009): "The Unemployment Volatility Puzzle: Is Wage Stickiness the Answer?" Econometrica, 77, 1339-1369. [1329]

POSTEL-VINAY, F., AND J.-M. RoBIN (2002): "Equilibrium Wage Dispersion With Worker and Employer Heterogeneity,” Econometrica, 70, 2295-2350. [1327,1328]

Postel-VinaY, F., AND H. TURON (2010): "On-the-Job Search, Productivity Shocks and the Individual Earnings Process,” International Economic Review, 51, 599-629. [1333]

RoBin, J.-M. (2011): "Supplement to 'On the Dynamics of Unemployment and Wage Distributions'," Econometrica Supplemental Material, 79, http://www.econometricsociety.org/ ecta/Supmat/9070_data and programs.zip. [1336]

SHIMER, R. (2005): "The Cyclical Behavior of Equilibrium Unemployment and Vacancies," American Economic Review, 95, 25-49. [1327,1329,1340]

SteVENS, M. (2004): "Wage-Tenure Contracts in a Frictional Labour Market: Firms' Strategies for Recruitment and Retention,” Review of Economic Studies, 71, 535-551. [1331]

Dept. of Economics, Sciences Po, 28 rue des St. Pères, 75007 Paris, France and University College London; jeanmarc.robin@sciences-po.fr.

Manuscript received January, 2010; final revision received January, 2011. 